\title{
Decadal trends in beach morphology on the east coast of South Africa and likely causative factors
}

\author{
S. Corbella ${ }^{1,2}$ and D. D. Stretch ${ }^{1}$ \\ ${ }^{1}$ Centre for Research in Environmental, Coastal \& Hydrological Engineering, School of Civil Engineering, \\ University of KwaZulu-Natal, Durban, 4041, South Africa \\ ${ }^{2}$ eThekwini Municipality, Coastal Stormwater \& Catchment Management, P.O. Box 680, Durban, South Africa \\ Correspondence to: S. Corbella (corbellas@ durban.gov.za)
}

Received: 28 July 2011 - Revised: 29 June 2012 - Accepted: 17 July 2012 - Published: 13 August 2012

\begin{abstract}
Sandy shorelines are dynamic with constant changes that can cause hazards in developed areas. The causes of change may be either natural or anthropogenic. This paper evaluates evidence for shoreline changes and their causative factors using a case study on the east coast of South Africa. Beach morphology trends were found to be locationspecific, but overall the beaches show a receding trend. It was hypothesized that wave, tide, sea level and wind trends as well as anthropogenic influences are causative factors, and their contributions to shoreline changes were evaluated. Maximum significant wave heights, average wave direction, peak period and storm event frequencies all show weak increasing trends, but only the increases in peak period and wave direction are statistically significant. The chronic beach erosion cannot be attributed to wave climate changes since they are still too small to explain the observations. Instead, the impacts of sea level rise and reductions in the supply of beach sediments are suggested as the main causative factors. The analysis also identifies a trend in the frequency of severe erosion events due to storms that coincide with a 4.5-yr extreme tide cycle, which demonstrates the potential impact of future sea level rise.
\end{abstract}

\section{Introduction}

Shoreline erosion has long been a concern to engineers (Kinmont, 1954). Long-term erosion of a coastline has three main causes: sea level rise (e.g. Mather, 2008; Han et al., 2010), meteorological changes (Rouault et al., 2009, 2010) that may result in wave climate changes, and a reduction in sediment supply. Woodroffe (2003) identified waves as the principal energy source for erosion in the coastal zone, while erosion due to an increase in water level is a well-developed concept (Bruun, 1962). Zhang et al. (2004) analyzed the recovery of the US east coast barrier beaches and found that the beaches recovered to their long-term trend positions after storms regardless of storm severity. It was concluded that storm events are not responsible for long-term coastal erosion. Zhang et al. (2004) stated that, since no evidence has been given to show significant increases in storminess and since human interference is neither worldwide in extent nor uniform regionally, sea level rise is the most plausible contributor. It is worth noting that this statement may not consider dams and sediment mining on rivers that are arguably a worldwide human interference and contribute to long-term coastal erosion. Singh (1997) has previously analysed beach profile data from Trinidad and Tobago in an attempt to identify climate- related changes. Wave data were not considered, and Singh (1997) identified significant erosion. Since anthropogenic impacts such as sediment mining are not an issue in Trinidad, it was speculated that the erosion was from sea level rise.

Rivers play an important role in sediment supply and have been estimated to supply $80 \%$ of the global beach sediment (GESAMP, 1994). Reduction in sediment yield from rivers may be natural and anthropogenic. River sediments are exported to the sea almost exclusively during large floods (Rovira et al., 2005; Hsu et al., 2004), and so steady erosion trends may exist between these episodic flood events. Anthropogenic impacts on fluvial yield have become a global concern, and sediment mining and damming of rivers have been identified as significant impacts. Recent examples of related international research include Liquete et al. (2009); Huang (2011); Dai et al. (2008); Dang et al. (2010). 
In March 2007, the KwaZulu-Natal coastline on the east coast of South Africa suffered severe erosion due to an extreme storm event. This event stimulated local debate on whether the wave climate on the east coast of South Africa had changed causing more serious wave impacts more often. Changing wave climates have been investigated by numerous authors. In the Northern Hemisphere, Wang and Swail (2001, 2002) and Wang et al. (2004a) found that between 1958 and 1997 changes did occur in winter and autumn significant wave heights. Wang et al. (2004b) found that, in the past half century, the changes feature a significant increase in the number of strong winter and spring cyclones over the North Pacific, and of strong autumn and winter cyclones in the North Atlantic. Analysis of a 45-yr high resolution hindcast for the North Sea by Weisse and Stawarz (2004) showed that storm activity and extreme wave heights had increased from about 1960 onwards. Keim et al. (2004) concluded from their study of global climate models and empirical records that the past two decades have shown a decrease in the frequency of tropical storms but that there is a strong suggestion of an increase in the frequency of very strong (extreme) storms. Komar and Allan (2008) analysed $30 \mathrm{yr}$ of records from three wave buoys in the Atlantic. They found that there has been an increase in the number of occurrences of waves exceeding $3 \mathrm{~m}$, those generated by hurricanes, and in particular, the most extreme significant wave heights recorded. Theron et al. (2010) analysed wave data from Slangkop in South Africa and found that significant wave heights of storm events were increasing. There is uncertainty as to whether the above-mentioned documented trends are a result of anthropogenic climate change or are part of natural cycles (Ruggiero et al., 2010).

Decadal trends in beach morphology need to be considered in formulating coastal management plans to mitigate future risks. Through a case study of the east coast of South Africa, this paper aims to evaluate evidence for (1) trends in shoreline/beach evolution; (2) changes in wave climate such as trends in wave parameters and/or the frequency of extreme events; (3) links between shoreline/beach changes and wave climate trends or other causative factors.

\section{Methods}

\subsection{Case study site}

The city of Durban is a popular tourist destination on the east coast of South Africa (Fig. 1). Like many coastal cities, Durban is concerned about the risks posed by wave and sediment trends. The eThekwini Municipality (Durban's local authority) has adopted a pro-active approach to addressing climate change issues and has recently begun to quantify the potential impacts. Mather (2007) initiated this process when he analysed South African tide gauge recordings from between 1970 and 2003. He found that sea level rise in Durban is $2.7 \mathrm{~mm} \pm 0.05 \mathrm{~mm}$ per year at a $95 \%$ confidence level. A

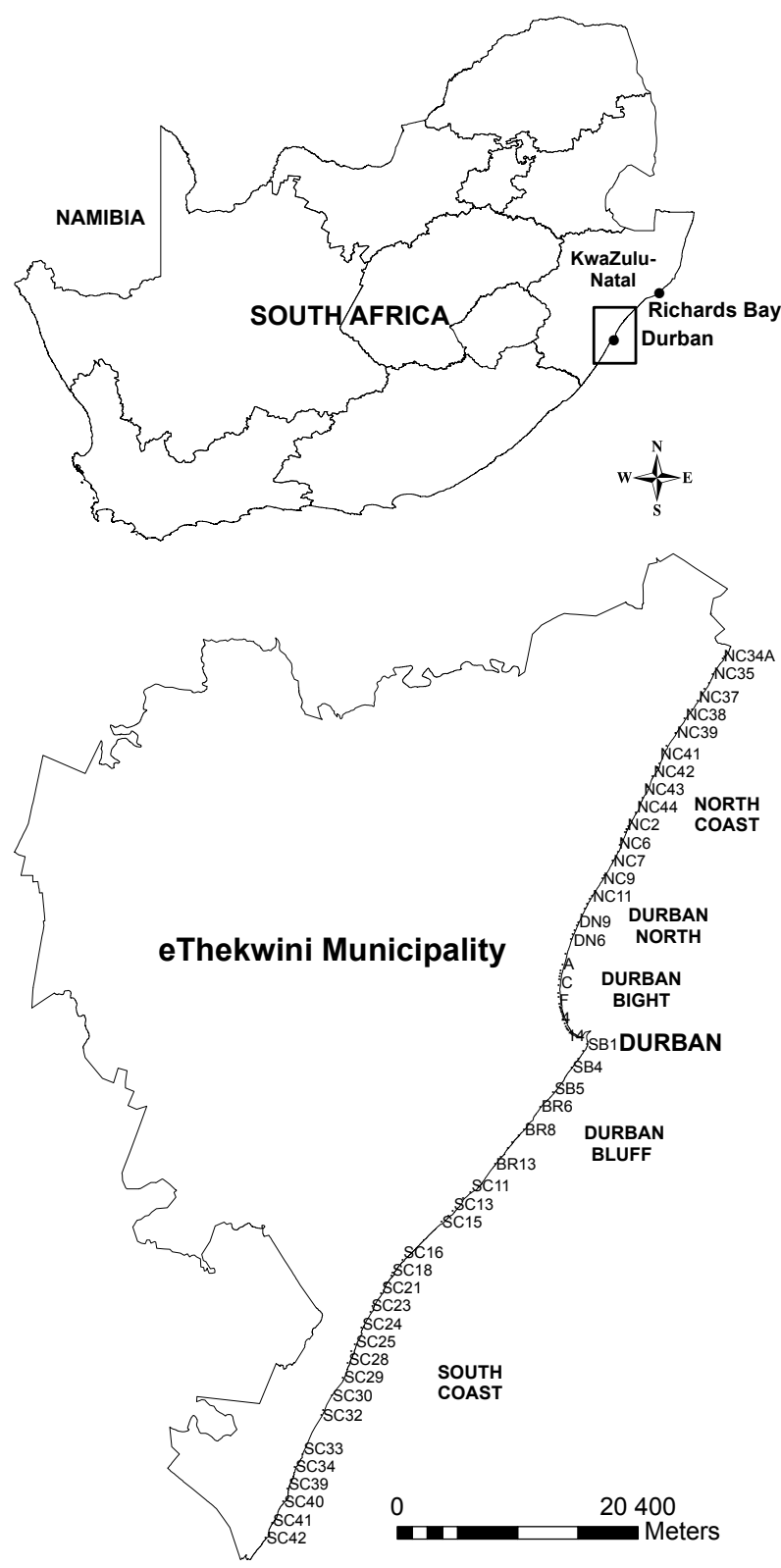

Fig. 1. A map of the South African coastline showing the location of the case study site at Durban and Richards Bay and a map of the eThekwini Municipality showing the beach profiles.

rise in sea level combined with possible changes in wave characteristics can cause significant impacts. This has motivated further research into the trends of the east coast wave climate and erosion of its beach profiles.

\subsection{Beach profile data and analysis}

The Durban Bight (Profiles A-23 in Fig. 3a) has historically suffered from erosion as a result of the adjacent harbour activities. Consequentially, the bight has a comprehensive data set from 1973. As the municipality grew, so did 


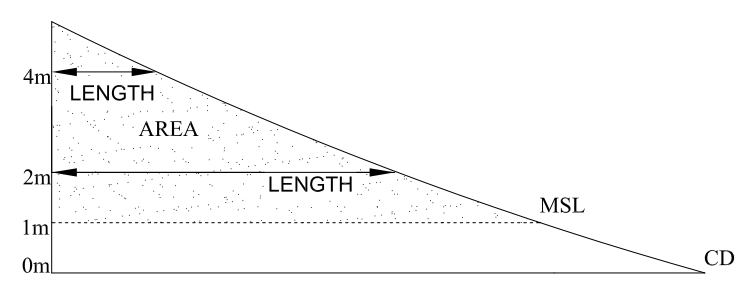

Fig. 2. Beach profile area (volume per meter) above $1 \mathrm{~m}$ chart datum (CD) (approximately mean sea level, MSL) and beach profile length at the $2 \mathrm{~m}$ and $4 \mathrm{~m} \mathrm{CD}$ contour.

the monitoring of profiles and some profiles have been introduced to the monitoring programme as recently as 2007. The analysis of the profiles was restricted to those with data including or preceding the year 1992. The profiles are measured at least every three months using a theodolite referenced to fixed benchmarks. Profile lengths were analysed at the $1 \mathrm{~m}, 2 \mathrm{~m}$ and $4 \mathrm{~m}$ chart datum (CD) contours as they approximate the swash zone. Profile areas (volume per meter) and beach volumes were also analysed and were calculated above $1 \mathrm{~m} \mathrm{CD}$ (about mean sea level at this location). The definition of profile area or volume per meter and profile length are shown in Fig. 2. The beach volume was calculated from the profile areas and the distances between the profiles using the end areas method.

The available data can be summarized as comprising three time histories: (1) a time series of profile lengths at the $1 \mathrm{~m}$, $2 \mathrm{~m}$ and $4 \mathrm{~m} \mathrm{CD}$ contour; (2) a time series of profile areas or volumes per meter; and (3) a time series of beach volumes.

\subsection{Singular spectrum analysis}

Singular spectrum analysis (SSA) was performed on the profiles to filter the data and identify any trends. SSA decomposes a time series into a sum of constituent parts that characterize variations over different time scales. The reader is referred to Golyandina et al. (2001) or Hassani (2007) for detailed descriptions of SSA.

SSA was done on all the profile data from 1973 to 2009 and from 1995 to 2009. The beach profiles were grouped into blocks based on their position and data record. Four blocks were created: B-F; 1-18; 19-23; BR6-BR9 (see Fig. 3). The end areas method was then used to create block volumes. A single slowly varying eigenvector was used to approximate the volume time series trends.

SSA was also used to gauge the appropriateness of inferring a cause and effect relationship between sea storm trends and erosion trends. Wave height and tidal trends were compared to the four block volumes, and Kendall's $\tau_{\mathrm{B}}$ correlation coefficients were used to identify their association. Finally, SSA was used to analyze the trends in local wind speed data for the period 1995 to 2009 and to assess any influence on erosion trends.

\subsection{Wave and wind data}

Rossouw (1984) reviewed all of South Africa's available wave data and concluded that only the wave recording buoy (Datawell Waverider Buoy) data were reliable enough to use for design work. This limited Durban's wave data set to $18 \mathrm{yr}$ between 1992 and 2009 from two Waverider buoys and an acoustic doppler current profiler (ADCP). The two Durban Waveriders have a comprehensive set of data, while the Durban ADCP data have large gaps and are measured at a shallower water depth than the other instruments (Table 1). Diedericks (2009) found that the Richards Bay Waverider data have a good correlation with Durban's data. His conclusions were verified by finding a Pearson correlation between the Richards Bay data, Durban's Waveriders and the ADCP. There is a strong correlation between the Waveriders but not the ADCP. The Richards Bay data were therefore used in place of the ADCP as well as to supplement any missing data. Since any trends in the Durban data may represent the shoaling and refraction effects of waves being recorded in different water depths, the Richards Bay data were also analysed to confirm the results of the Durban data. The Durban data will be the focus of this paper, and the Richards Bay data will only be referred to as required.

The Waveriders sample at a rate of $10 \mathrm{~Hz}$, and wave statistics are calculated at $102 \mathrm{~s}$ intervals. The maximum wave parameters were then extracted at three hour intervals, and the following parameters were analysed annually and seasonally: The maximum wave height $H_{\max }$ is the largest wave recorded in a recording period; the significant wave height $H_{\mathrm{s}}$ which in deep water is equal to $4 \sqrt{m o}$ where $m o$ is the area under the wave spectrum; the peak period $T_{\mathrm{p}}$ is the period at which the maximum energy density occurs and is the inverse of the peak energy frequency $f_{\mathrm{p}}, T_{\mathrm{p}}=1 / f_{\mathrm{p}}$ and the average peak period and average significant wave height. The average wave direction is the azimuth from true north and was analyzed as a vector of significant wave height.

Storm events were also analyzed in terms of occurrence, duration and calm period. A storm event was defined as a wave event that exceeded a $3.5 \mathrm{~m}$ significant wave height. The duration was defined as the time from when the significant wave heights exceeded the $3.5 \mathrm{~m}$ threshold until the significant wave heights fell below this threshold for at least two weeks. The two week interval is intended to ensure independent consecutive storm events and is similar to that used in previous work (e.g. Callaghan et al., 2008). The Spearman autocorrelation coefficient of $H_{\mathrm{s}}$ shows a decay to low values $(<0.1)$ within two weeks, which supports the assumption that the selected storm events are statistically independent. The calm period was defined as the time between consecutive storm events.

A linear regression analysis was performed on the wave data to evaluate trends.

Wind measurements at $20 \mathrm{~min}$ intervals from the Durban port were obtained for the years 1995 and 2009. The 


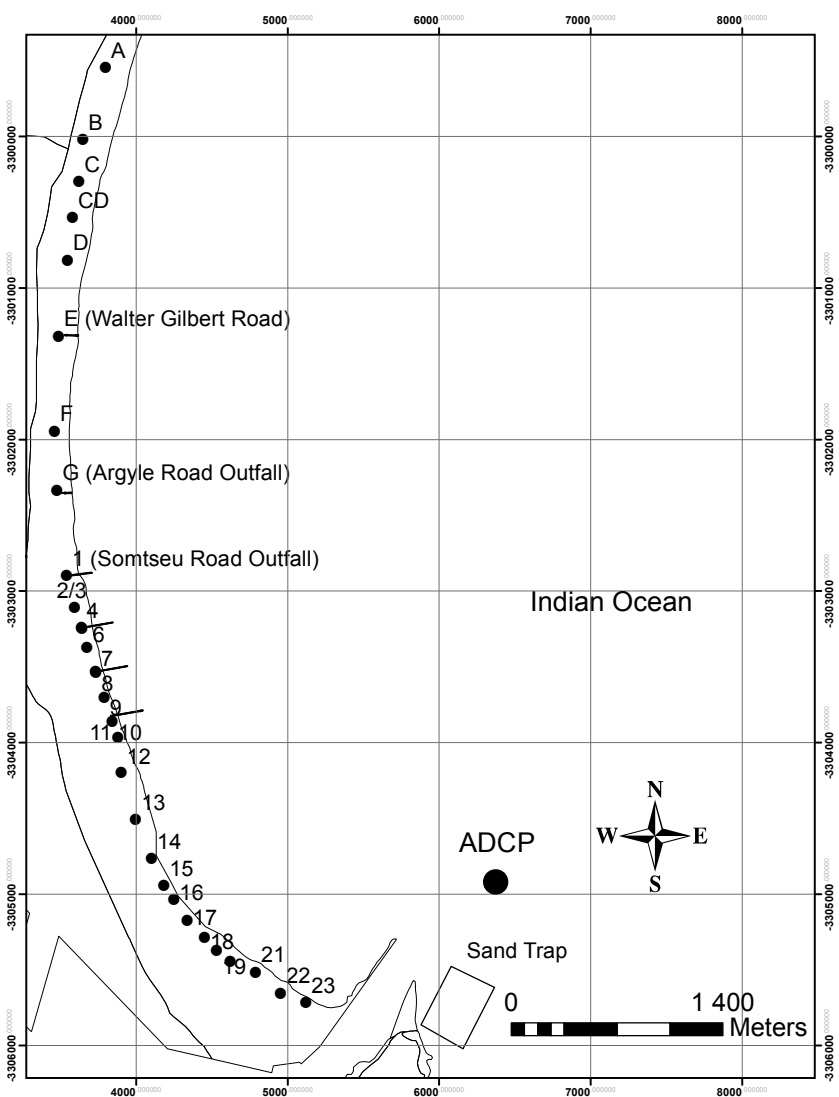

(a)

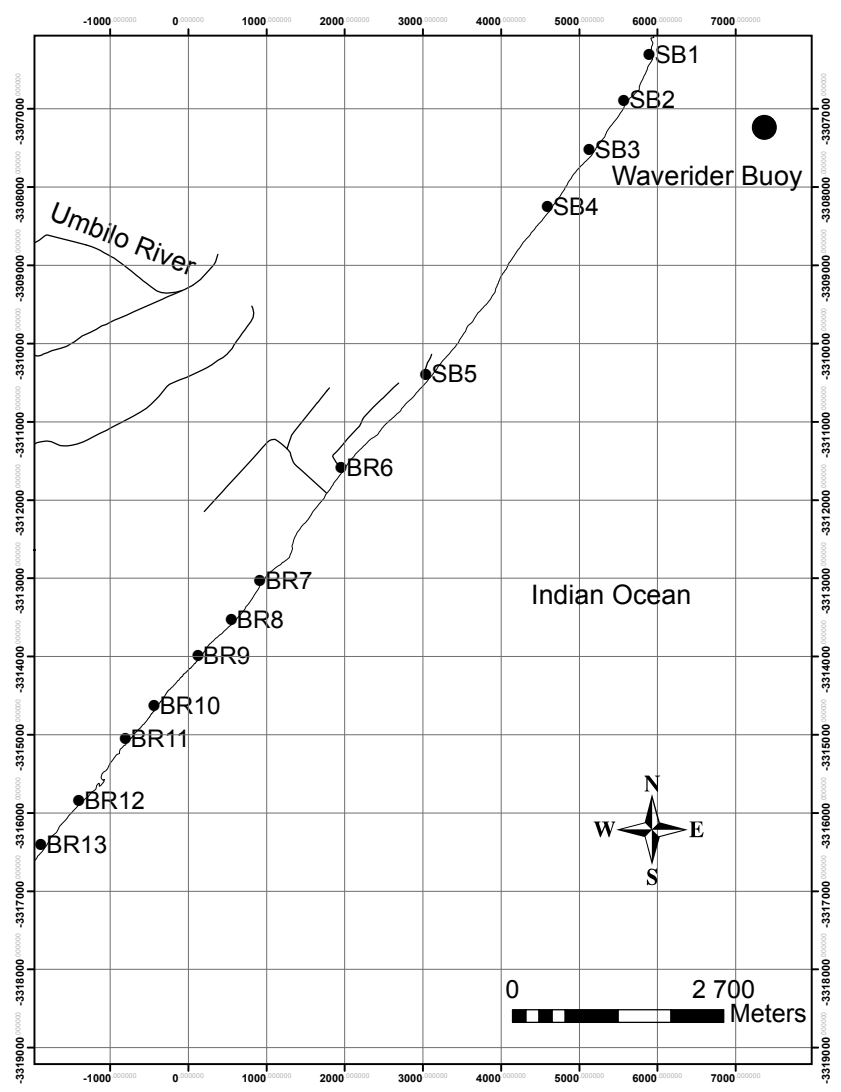

(b)

Fig. 3. Locations of beach profiles and wave recording instruments. Coordinate system: Lo 31 WGS84. (a) Profiles A to 23 of the Durban Bight and the Durban Waverider Buoy (b) Profiles BR6 to BR10 of the Durban Bluff Beaches and the Durban ADCP.

Table 1. Historical wave recording instruments, their operating periods and water depth.

\begin{tabular}{lcc}
\hline Instrument & Period of operation & Depth (m) \\
\hline Durban Waverider & $1992-2001$ & 42 \\
Durban ADCP & $2002-2006$ & 15 \\
Durban Waverider & $2007-2009$ & 30 \\
Richards Bay Waverider & $1992-2009$ & 22
\end{tabular}

measurements were at elevations between $80 \mathrm{~m}$ and $90 \mathrm{~m}$ above sea level. The data were corrected for altitude using a 1/7-th power law approximation for the velocity profile. Wind data were analysed similarly to the wave data using a threshold value of $14 \mathrm{~m} \mathrm{~s}^{-1}$.

\section{Results}

\subsection{Beach profile trends}

The profile trends were extracted from the beach volume time series using SSA. The trends were limited to a single slowly varying eigenvector. Figure 4 shows the time series for the block volumes of B-F, 1-18, 19-23 and BR6-BR9. Figure 4 illustrates that beaches have been eroding over the $37 \mathrm{yr}$ period in an approximately linear manner. Blocks B-F, 1-18 and 19-23 have more erratic beach volumes relative to BR6BR9. This is because they are more strongly influenced by the sand bypass scheme and the beach profile evolution is unnatural.

\subsection{Quantifying long-term trends}

Following the results of the singular spectrum analysis, it was evident that the long-term trends could be approximated by a linear trend. Long-term beach profile trends were therefore analyzed using linear regression. Figure 5 shows the results of the long-term analysis of profile volumes per meter from $1973 / 1988$ to 2009 . Figure 6 similarly shows the results from 


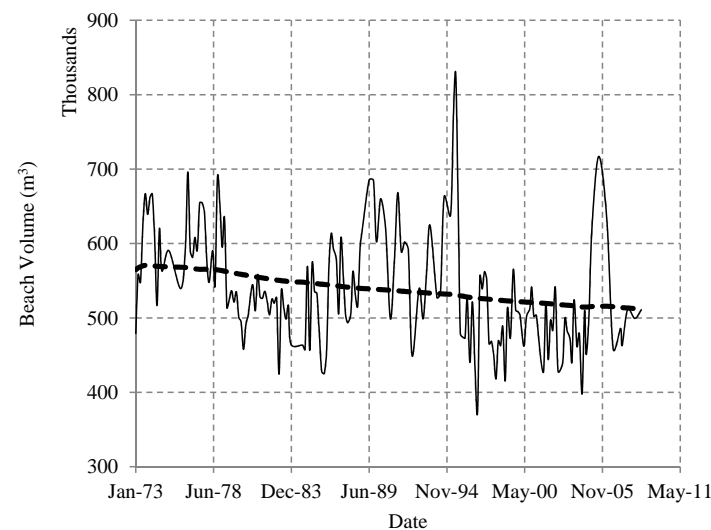

(a)

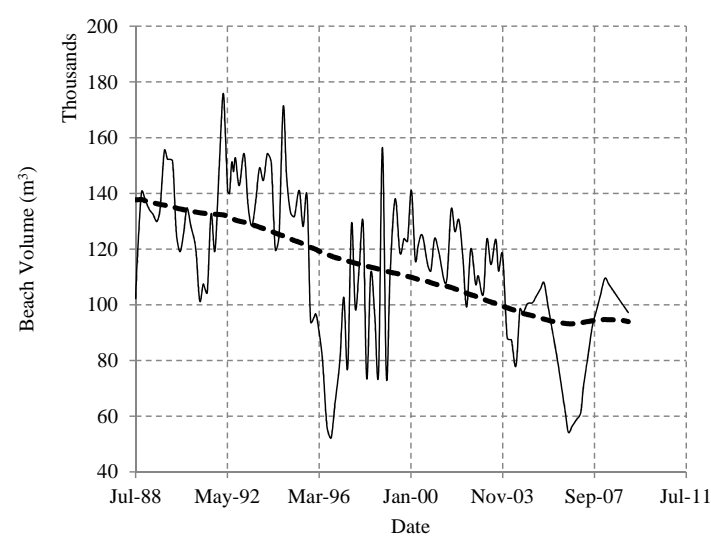

(c)

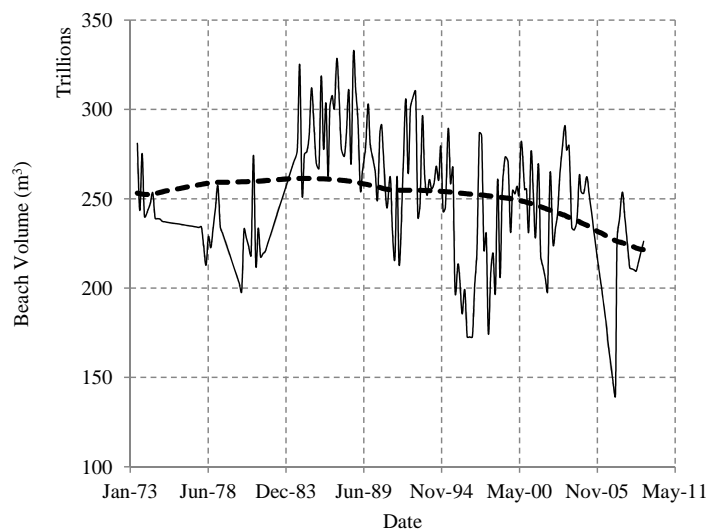

(b)

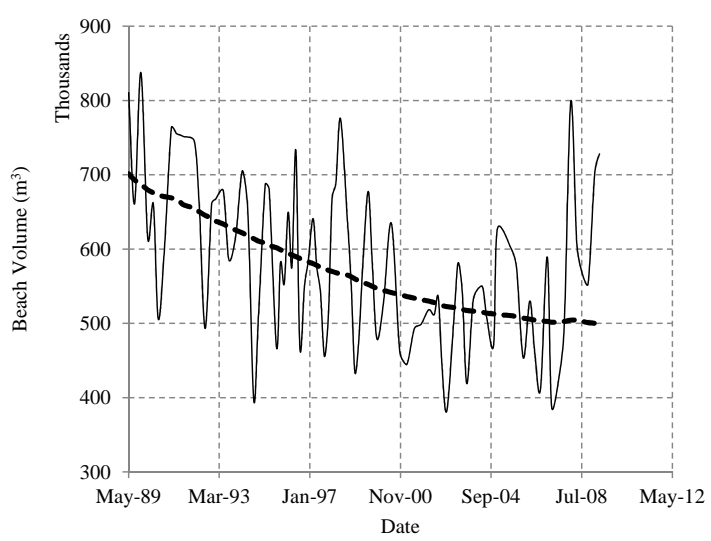

(d)

Fig. 4. Singular spectrum analysis of beach volume blocks showing the original time series by the solid line and the reconstructed time series shown by the dashed line. Each data point represents a 3 month interval. (a) Block volume B-F, (b) Block volume 1-18, (c) Block volume 19-23, (d) Block volume BR6-BR9 (refer to Fig. 3).

1995 to 2009. The majority of the central beach profiles (4 to 18) have been increasing over the past $37 \mathrm{yr}$ (Fig. 5). This is expected as it is an area intensely managed by the eThekwini Municipality in an attempt to mitigate the erosion potential developed by the harbour breakwaters and maintenance dredging. The Vetch's Bight (19 to 23) and the majority of the Bluff beaches (BR6 to BR10) have been receding over the years (Figs. 5 and 6).

Table 2 shows the percentage of profiles with regards to volume and length that have increasing or decreasing trends. The percentage of statistically significant trends is also shown. Statistically significant trends are defined as trends whose $95 \%$ confidence intervals have the same signs. Over $37 \mathrm{yr}$, the length of the $2 \mathrm{~m}$ and $4 \mathrm{~m} \mathrm{CD}$ contours has been increasing for almost $60 \%$ of the profiles (Table 2). However, over the same time period, almost $60 \%$ of the profile areas and $100 \%$ of the beach volumes have been decreasing. This implies that the $2 \mathrm{~m}$ and $4 \mathrm{~m} \mathrm{CD}$ contours describe profile shape changes but not losses or gains. The volume per

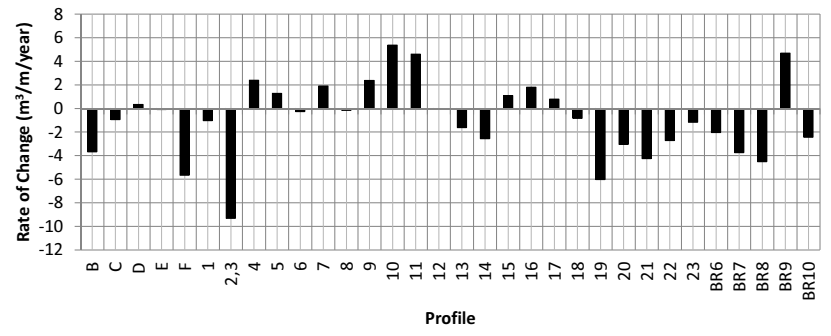

Fig. 5. Profile volume per meter annual rate of change (1973/19882009).

meter and volume measurements are therefore more appropriate for quantifying long-term erosion trends.

The $15 \mathrm{yr}$ of data show approximately $70 \%$ of the profiles to be decreasing in terms of length and area. 
Table 2. Type of trend experienced by the beach length at the $2 \mathrm{~m}$ and $4 \mathrm{~m} \mathrm{CD}$ contour, volume per meter and volume during the period of $1973 / 1988$ to 2009 and the beach length at the $1 \mathrm{~m} \mathrm{CD}$ contour and volume per meter during the period of 1995 to 2009 . The percentage of data contributing to the type of trend is shown as well as the percentage of statistically significant data.

\begin{tabular}{cccccc}
\hline \multicolumn{2}{c}{ Trend } & \multicolumn{2}{c}{ Increase } & \multicolumn{2}{c}{ Decrease } \\
\hline \multirow{2}{*}{ Time Period } & Measurement & Data (\%) & Statistically Significant (\%) & Data (\%) & Statistically Significant (\%) \\
\hline \multirow{2}{*}{$1973 / 1988-2009$} & Length (2 m CD) & 59 & 90 & 41 & 79 \\
& Length (4 m CD) & 56 & 84 & 44 & 80 \\
& Volume per meter & 33 & 91 & 67 & 77 \\
& Volume & 0 & NA & 100 & 100 \\
\hline \multirow{2}{*}{$1995-2009$} & Length (1 m CD) & 27 & 25 & 73 & 53 \\
& Volume per meter & 30 & 46 & 70 & 58 \\
\hline
\end{tabular}

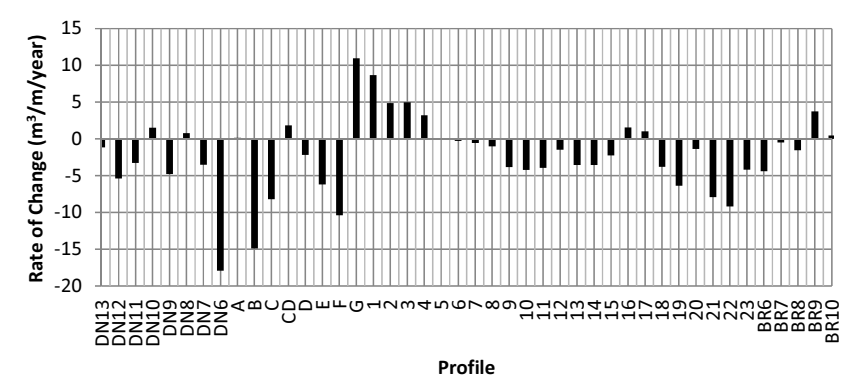

Fig. 6. Profile volume per meter annual rate of change (1995-2009)

\subsubsection{Beach gains}

From Fig. 6, it can be seen that the beaches have had significant gains from profiles $\mathrm{G}$ to 4 in descending order. This is a result of stormwater outfalls stretching across the shoreline. Profile 4 marks the location of the Bay of Plenty groyne. Profile 1 corresponds to Somtseu Road stormwater outfall, and profile $\mathrm{G}$ is Argyle Road stormwater outfall. Profile BR9 and BR10 are the only profiles in the Bluff region that have accreted, which is also a result of stormwater outfalls. Unlike the semi-permeable Bay of Plenty groyne which is designed to retard the littoral transport, the stormwater outfalls are intended only for discharging stormwater into the ocean. However, the large concrete stormwater outfalls intercept the littoral transport and trap sand on their up-drift sides. This causes accretion on the up-drift beaches but consequentially starves down-drift beaches and induces erosion.

\subsubsection{Beach losses}

Other than isolated gains, Figs. 5 and 6 show that most of the profiles have lost sediment. It is no surprise that, north of the groyne field ( $\mathrm{G}$ and 4 ), there is a high loss rate which decreases gradually until it becomes a gain at profile CD. As previously explained, this happens because the groynes trap sediment on their up-drift side and starve the down-drift beaches of sediment. The remaining profile losses cannot be attributed to beach structures. They could be the result of a reduction in sediment supply to the beaches or a result of increased frequency and or intensity of storms. The potential contribution of these three factors is discussed in Sect. 3.5 to Sect. 3.8.

\subsection{Wave parameter trends}

Tables 3 and 4 show the annual rate of change of wave parameters over the past 18 yr for Durban and Richards Bay respectively. Wave directions were only measured at Durban after 2002 while Richards Bay has wave direction data from 1997 onwards.

Table 3 shows that the maximum $H_{\max }$ has been slowly increasing in each season except for spring which has not experienced a change. The maximum $H_{\mathrm{s}}$ also shows an increasing trend in all seasons except spring where it has been decreasing. Average $H_{\mathrm{s}}$ shows virtually no annual change.

The maximum $T_{\mathrm{p}}$ behaves similarly to the maximum $H_{\mathrm{s}}$. Average wave direction is increasing in all the seasons except winter where it is slowly decreasing.

The $95 \%$ confidence intervals in Table 3 show that the majority of the calculated trends are not statistically significant. The only exceptions are the increasing trends in average and maximum $T_{\mathrm{p}}$, and in the average wave direction.

Richards Bay data (Table 4) show somewhat different results to the Durban data. In this case, the only statistically significant trends are in autumn and show a decrease in the maximum $T_{\mathrm{p}}$ and an increase in the average $T_{\mathrm{p}}$. Furthermore, the average autumn wave direction is decreasing, which contrasts with increases in the other seasons, but the latter are not statistically significant at the $95 \%$ confidence level.

The limitations of short duration data are illustrated by considering the effects of the 2007 storm event. The storm occurred in March and therefore affects the results for the autumn season in particular, but also affects those for the data set as a whole. For Durban, without the 2007 event, the autumn season showed a decreasing trend in maximum $H_{\mathrm{s}}$. 


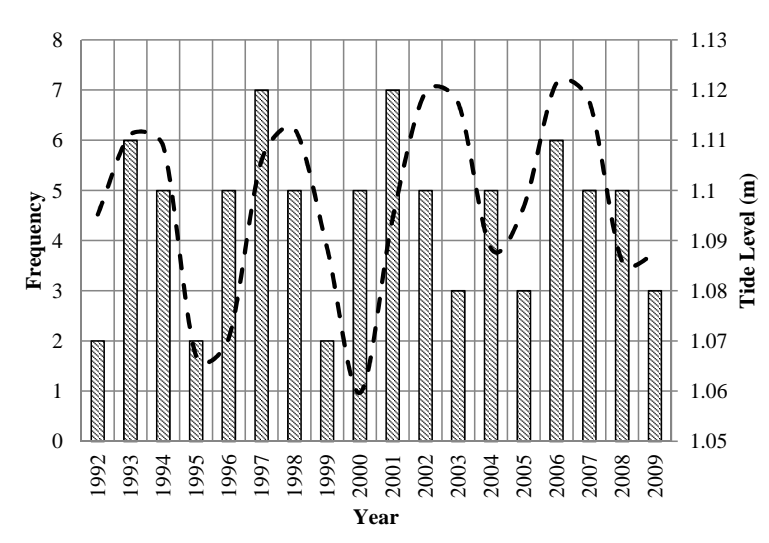

Fig. 7. Frequency of events exceeding $3.5 \mathrm{~m}$ shown by the column chart and simulated highest astronomical tides of each year relative to mean sea level shown by the dashed line.

This single storm event was large enough to change the trend, and similarly for the combined all season results. In the case of Richards Bay, the 2007 event did not affect the trends of the combined seasons but did affect the autumn trend. These results, taken together with the inconsistencies between the two locations, indicate that trends in the wave parameters cannot yet be deduced with confidence from the available data. A much longer data record is required to balance out the effects of extreme events such as the 2007 storm event.

\subsection{Storm trends}

All the storm events, as per the definition in Sect. 2.4, were extracted from the data to determine if there had been an increasing trend in the frequency and duration and a decreasing trend in the calm period of these storm events. Figure 7 shows the frequency of events exceeding an $H_{\mathrm{S}}$ of $3.5 \mathrm{~m}$.

The data show an increasing trend in the frequency of events exceeding $3.5 \mathrm{~m}$ at a rate of $0.015 \pm 0.16$ events per year which is not statistically significant at the $95 \%$ confidence level. There does however seem to be a four year cycle in which a multitude of events occurs within a year, namely 1993, 1997, 2001 and 2006. This cycle is similar to the time of the lunar perigee coinciding with either the March or September equinox, a $4.5 \mathrm{yr}$ extreme tide cycle (Pugh, 1987). The tide levels shown in Fig. 7 were simulated from the general astronomical tide formula using the 8 most relevant astronomical constituents. Since both tidal levels and storm frequency are associated with erosion, the occurrence of the two mechanisms simultaneously is a significant erosion concern. The cycle is not as clear in the Richards Bay data and is not evident in the wind data. Table 5 shows the trend in storm frequency, duration and calm period. The storm events and wind data show a decreasing trend in duration and calm period. The smaller the calm period, the less time the beaches have to recover from storm events. However, once again the trends are not statistically significant at the $95 \%$ confidence level. The Richards Bay results are similar.

\subsection{Link between sea storms and erosion trends}

Figure 8a-d compares the SSA-filtered significant wave height trends to the volume trends in blocks B-F; 1-18; 19-23 and BR6-BR9. Table 6 gives the Kendall's $\tau_{\mathrm{B}}$ correlation coefficients (with corresponding p-values) between wave heights and beach volumes. The correlation coefficients for the first three blocks are small and negative, but not statistically significant at a $95 \%$ confidence level. However, the correlations for block BR6-BR9 are larger and statistically significant. A negative correlation is expected because wave height is a driver for erosion that reduces beach volumes (e.g. Woodroffe, 2003). However, the profiles north of the harbour entrance are strongly influenced by the sand bypass system. The trends in erosion for blocks B-F; 1-18; 19-23 are better explained by variations in the sediment supply from the sand-pumping scheme, as discussed further in Sect. 3.8.

\subsection{Link between water levels and erosion trends}

Figure 9 shows the tide trends and the four block volume trends deduced from SSA, while correlation coefficients are compiled in Table 7. The plots show a distinctive dip in beach volumes during the peak in tidal trend. Blocks B-F and 1-18 have been recorded over two tidal peaks and have the largest correlation coefficients with a mean of -0.25 and with $p$ values less than 0.002 (Table 7). A significant negative correlation is again expected because higher water levels extend the onshore penetration of wave energy. Blocks 19-23 and BR6-BR9 are only recorded over one peak of the tidal trend, and both of these blocks have weaker correlations with the tidal trend that are not statistically significant at the $95 \%$ confidence level. The weaker correlation at block 19-23 may be related to effects of the sand bypass system, while blocks BR6-BR9 have a weak correlation because they are dominated by chronic erosion.

The Bruun rule (Bruun, 1962) provides a simple relationship between sea level rise and profile retreat, although it is not always appropriately applied (see e.g. Cooper and Pilkey, 2004). In the present study, it was used to identify and evaluate the contribution of sea level rise to the observed chronic erosion. Closure depths were calculated for profiles C, D, F and 13 (Fig. 3), and the Bruun rule was applied to them. A linear sea level rise of $0.0027 \mathrm{~m} \mathrm{yr}^{-1}$ was assumed based on the estimate by Mather (2007). Table 8 shows a comparison between measured volume changes and those estimated by the Bruun rule. The average measured loss in profile volume is $1.97 \mathrm{~m}^{3} \mathrm{~m}^{-1} \mathrm{yr}^{-1}$ with an estimated average loss due to sea level rise of $2.06 \mathrm{~m}^{3} \mathrm{~m}^{-1} \mathrm{yr}^{-1}$. Profile D has a measured annual gain and, if we remove it from the average, the measured volume increases to $2.74 \mathrm{~m}^{3} \mathrm{~m}^{-1} \mathrm{yr}^{-1}$. Taken together with the correlation between tide levels and erosion, these 
Table 3. Annual rate of change of Durban's wave parameters. The bracketed values are the $95 \%$ confidence intervals.

\begin{tabular}{lrrrrr}
\hline Parameter & All seasons & Summer & Autumn & Winter & Spring \\
\hline Maximum $H_{\max }(\mathrm{m})$ & $0.04(-0.09 ; 0.17)$ & $0.04(-0.09 ; 0.16)$ & $0.09(-0.12 ; 0.30)$ & $0.07(-0.06 ; 0.19)$ & $0.0(-0.11 ; 0.11)$ \\
Maximum $H_{\mathrm{S}}(\mathrm{m})$ & $0.03(-0.08 ; 0.14)$ & $0.03(-0.03 ; 0.08)$ & $0.04(-0.11 ; 0.19)$ & $0.01(-0.06 ; 0.07)$ & $-0.01(-0.08 ; 0.06)$ \\
Average $H_{\mathrm{S}}(\mathrm{m})$ & $-0.01(-0.02 ; 0.01)$ & $0.00(-0.02 ; 0.01)$ & $0.00(-0.05 ; 0.04)$ & $0.00(-0.03 ; 0.02)$ & $-0.01(-0.02 ; 0.00)$ \\
Maximum $T_{\mathrm{p}}(\mathrm{s})$ & $0.14(0.05 ; 0.22)$ & $0.10(-0.08 ; 0.27)$ & $0.14(-0.02 ; 0.31)$ & $0.17(0.08 ; 0.26)$ & $0.13(-0.02 ; 0.28)$ \\
Average $T_{\mathrm{p}}(\mathrm{s})$ & $0.07(0.02 ; 0.13)$ & $0.06(0.03 ; 0.09)$ & $0.26(0.03 ; 0.49)$ & $0.11(-0.03 ; 0.24)$ & $0.04(-0.002 ; 0.09)$ \\
Average Direction (Deg.) & $0.91(0.12 ; 1.7)$ & $3.5(-3.8 ; 11)$ & $0.71(-2.5 ; 3.9)$ & $-0.06(-0.53 ; 0.41)$ & $0.25(-0.67 ; 1.2)$ \\
\hline
\end{tabular}

Table 4. Annual rate of change of Richards Bay's wave parameters. The bracketed values are the $95 \%$ confidence intervals.

\begin{tabular}{|c|c|c|c|c|c|}
\hline Parameter & All seasons & Summer & Autumn & Winter & Spring \\
\hline Maximum $H_{\max }(\mathrm{m})$ & $0.08(-0.05 ; 0.21)$ & $-0.01(-0.12 ; 0.09)$ & $0.06(-0.14 ; 0.26)$ & $0.01(-0.09 ; 0.10)$ & $0.08(-0.11 ; 0.11)$ \\
\hline Maximum $H_{\mathrm{s}}(\mathrm{m})$ & $0.07(-0.04 ; 0.17)$ & $0.01(-0.04 ; 0.06)$ & $0.04(-0.09 ; 0.18)$ & $-0.00(-0.05 ; 0.05)$ & $0.06(0.01 ; 0.12)$ \\
\hline Average $H_{\mathrm{S}}(\mathrm{m})$ & $-0.00(-0.01 ; 0.01)$ & $-0.00(-0.01 ; 0.01)$ & $-0.00(-0.02 ; 0.01)$ & $-0.00(-0.02 ; 0.01)$ & $0.00(-0.01 ; 0.01)$ \\
\hline Maximum $T_{\mathrm{p}}(\mathrm{s})$ & $-0.05(-0.25 ; 0.15)$ & $-0.22(-0.46 ; 0.03)$ & $-0.22(-0.39 ;-0.05)$ & $0.01(-0.18 ; 0.21)$ & $0.02(-0.22 ; 0.26)$ \\
\hline Average $T_{\mathrm{p}}(\mathrm{s})$ & $0.02(-0.00 ; 0.05)$ & $0.01(-0.05 ; 0.06)$ & $0.05(0.01 ; 0.08)$ & $0.04(-0.01 ; 0.08)$ & $-0.01(-0.09 ; 0.07)$ \\
\hline Average Direction (Deg.) & $0.07(-0.15 ; 0.28)$ & $0.18(-0.49 ; 0.84)$ & $-0.75(-1.12 ;-0.37)$ & $0.16(-0.49 ; 0.80)$ & $-0.02(-0.58 ; 0.54)$ \\
\hline
\end{tabular}

Table 5. Annual rate of change of storm attributes with $95 \%$ confidence bounds.

\begin{tabular}{lr}
\hline Storm attribute & Annual rate of change \\
\hline Frequency (no.) & $0.015(-0.14 ; 0.18)$ \\
Duration (h) & $-0.44(-2.15 ; 1.27)$ \\
Calm period (h) & $-28.4(-150 ; 93)$ \\
\hline
\end{tabular}

Table 6. Kendall's $\tau_{\mathrm{B}}$ correlation coefficients and corresponding $\mathrm{p}$ values between significant wave heights and beach volumes.

\begin{tabular}{lrr}
\hline Correlation variables & Kendall's $\tau_{\mathrm{B}}$ & $\mathrm{p}$-value \\
\hline (Volumes B-F) $: H_{\mathrm{S}}$ & -0.13 & 0.063 \\
(Volumes 1-18) $: H_{\mathrm{S}}$ & -0.059 & 0.38 \\
(Volumes 19-23) $: H_{\mathrm{S}}$ & -0.13 & 0.052 \\
$\left(\right.$ Volumes BR6-BR9) $: H_{\mathrm{S}}$ & -0.32 & $1.3 \times 10^{-6}$ \\
\hline
\end{tabular}

results suggest that sea level rise is contributing significantly to chronic erosion.

\subsection{Link between wind and erosion}

The wind data show a strong seasonal trend in which high wind speeds are experienced from August to December. The majority of the wind in all seasons is from the northeast and southwest, and there is no evidence of directional trends or associated erosion consequences. Figure 10 shows the seasonal trends in the wind speed and its relationship with erosion. There is no correlation between wind and erosion
Table 7. Kendall's $\tau_{\mathrm{B}}$ correlation coefficients and corresponding $\mathrm{p}$ values between tide levels and beach volumes.

\begin{tabular}{lrr}
\hline Correlation variables & Kendall's $\tau_{\mathrm{B}}$ & p-value \\
\hline Volume B-F : tide level & -0.15 & $4 \times 10^{-3}$ \\
Volume 1-18 : tide level & -0.34 & $7.7 \times 10^{-12}$ \\
Volume 19-23 : tide level & -0.11 & 0.056 \\
Volume BR6-BR9 : tide level & -0.099 & 0.10 \\
\hline
\end{tabular}

Table 8. Comparison of measured annual erosion volumes $\left(\mathrm{m}^{3} \mathrm{~m}^{-1}\right)$ and estimated annual erosion volumes $\left(\mathrm{m}^{3} \mathrm{~m}^{-1}\right)$ calculated from the Bruun rule using a sea level rise of $0.0027 \mathrm{~m} \mathrm{yr}^{-1}$.

\begin{tabular}{lrr}
\hline Profile & $\begin{array}{r}\text { Measured erosion } \\
\left(\mathrm{m}^{3} \mathrm{~m}^{-1} \mathrm{yr}^{-1}\right)\end{array}$ & $\begin{array}{r}\text { Estimated erosion } \\
\left(\mathrm{m}^{3} \mathrm{~m}^{-1} \mathrm{yr}^{-1}\right)\end{array}$ \\
\hline $\mathrm{C}$ & 0.95 & 1.51 \\
$\mathrm{D}$ & -0.34 & 1.99 \\
$\mathrm{~F}$ & 5.66 & 2.62 \\
13 & 1.62 & 2.12 \\
\hline Average & 1.97 & 2.06 \\
\hline
\end{tabular}




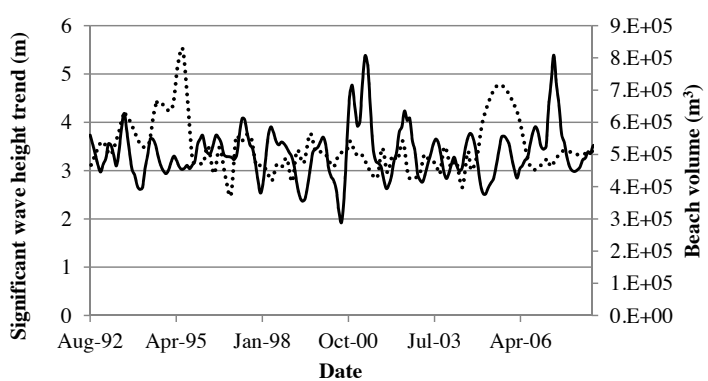

(a)

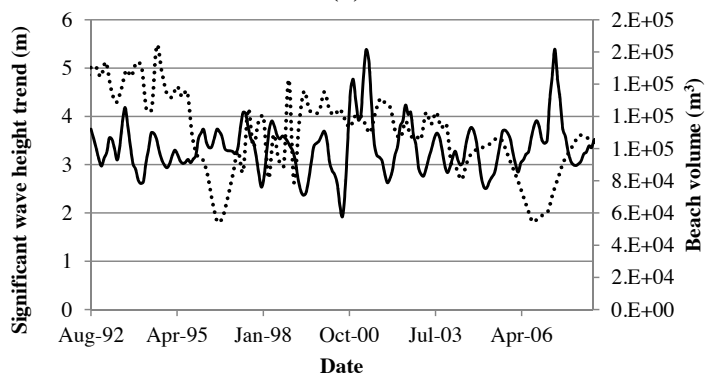

(c)

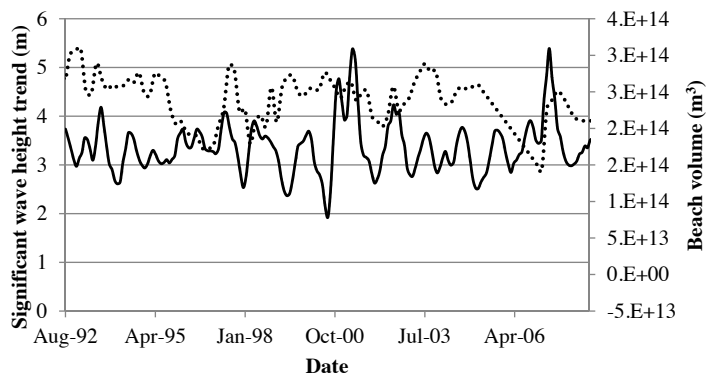

(b)

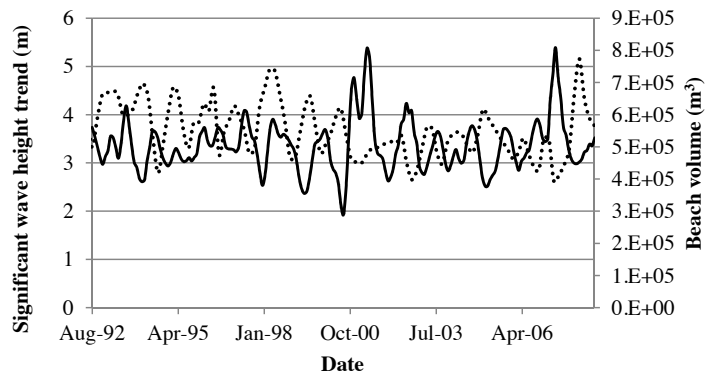

(d)

Fig. 8. The relationship between the significant wave height trends (shown by the solid line) and the beach volume trends (shown by the dotted line) for the blocks (a) B-F, (b) 1-18, (c) 19-23, (d) BR6-BR9 (refer to Fig.3).

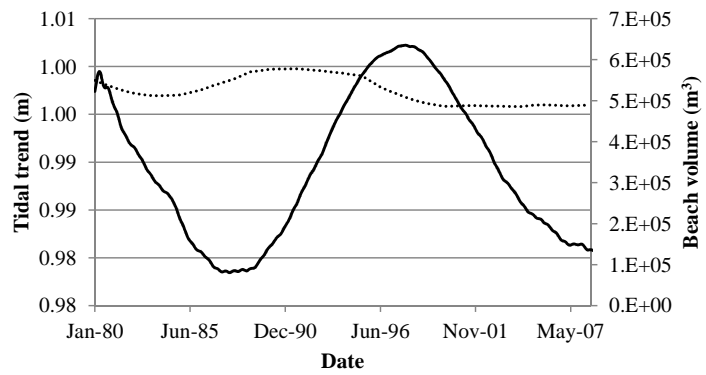

(a)

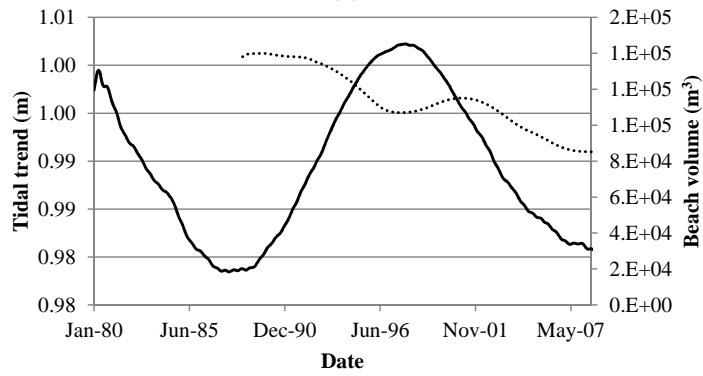

(c)

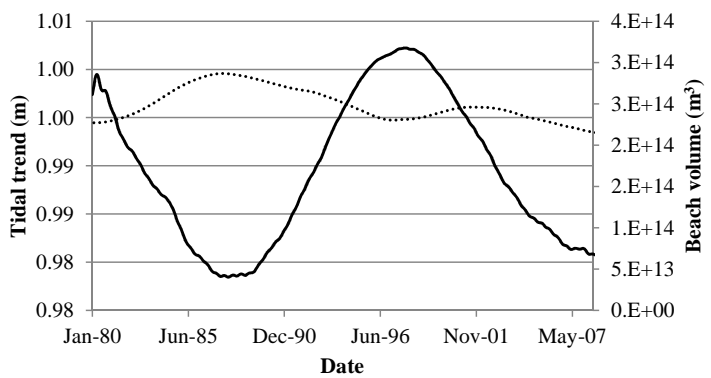

(b)

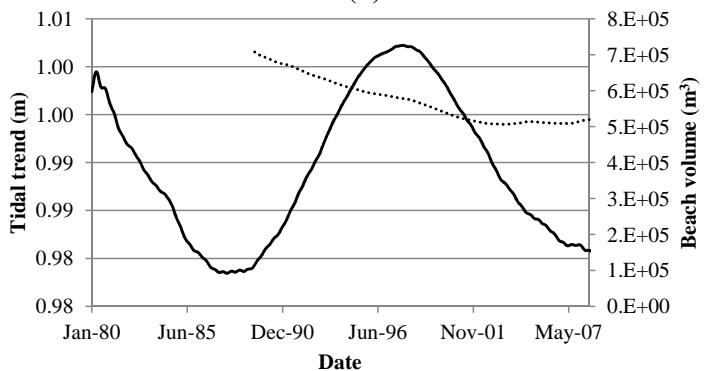

(d)

Fig. 9. The relationship between the tidal trends (shown by the solid lines) and the beach volume trends (shown by the dotted lines) for the blocks (a) B-F, (b) 1-18, (c) 19-23, (d) BR6-BR9 (refer to Fig. 3).

evident in Fig. 10a. Figure 10b and $\mathrm{c}$ have a weak negative correlation as a result of a long-term trough in wind speed coinciding with relatively high beach volumes. Overall, there is no clear evidence of significant correlation between wind speed and erosion in Fig. 10a-c. On the other hand, Fig. 10d shows the more exposed Bluff block, which is expected to be more dependent on the wind. The seasonal peaks in wind speed coincide with the troughs in beach volume and explain the seasonal variations in beach morphology. This is a significant result since, if seasonal winds can explain beach 
morphology, then long-term wind trends are a plausible contributor to long-term erosion. However, the available data set is too short to provide meaningful information on long-term trends.

\subsection{Link between sediment supply and erosion}

The relationship between sediment supply and erosion was investigated by considering dredger operations for Durban's sand bypass scheme. Durban's sand bypass system consists of a dredged sand trap (Fig. 3a) south of the harbour entrance that intercepts sand movements up the coast to prevent shoaling of the entrance channel. The sand trap is emptied by dredging, and the sediment is then pumped to the northern beaches. The Port of Durban regularly empties the sand trap, because excess sand blocks the harbour entrance channel and disrupts port activities. The sand trap is not expected to have a $100 \%$ trapping efficiency, but it is assumed that the pumped volume closely represents the sediment volume entering the sand trap and thus approximates the average littoral drift.

Figure 11 shows a time series of the volume of bypassed sand and the associated decreasing trend. This means that less sediment is being deposited on the beaches and suggests that the littoral transport is decreasing. Although the stormwater outfalls are responsible for erosion on up-drift profiles, they cannot be accountable for the net volume loss as the gains should balance the losses. A comparison of Fig. 11 and Fig. 8c illustrates the extent that the immediate beach profiles are dependent on the sediment supply. The least sediment was bypassed in the years 1996 and 2006 (Fig. 11), and the corresponding decrease in beach volume is clearly visible in Fig. 8c.

Only limited studies are available on the effects of dams and episodic storm events on sediment supply for the study area. These are discussed in Sect. 4.

\section{Discussion}

Durban's beach profile records are long enough to confidently say that the beaches have been eroding, but there is uncertainty concerning the factors that are contributing to this erosion.

Average $H_{\mathrm{s}}$ shows virtually no change, a result consistent with the findings of Perrie et al. (2004), while all the other parameters showed increases when considering the entire data set. The maximum $H_{\mathrm{s}}$, maximum $H_{\mathrm{max}}$ and maximum $T_{\mathrm{p}}$ are increasing in all seasons except spring. An increase in wave period is a concern as it has been shown to increase erosion (van Gent et al., 2008; van Thiel de Vries et al., 2008). The fact that large events are getting larger is consistent with recent findings elsewhere (Perrie et al., 2004; Lambert, 2004; Knutson and Tuleya, 2004; Weisse and Stawarz, 2004). Considering that spring is responsible for some of the largest historical storm events, it is surprising that it is moving against the general trend. This difference may imply a shift in the wave climate, which is consistent with the findings of Wang and Swail (2001, 2002); Wang et al. (2004a); Dodet et al. (2010). Rouault et al. (2010) hypothesised that a poleward shift of westerly winds as well as an increase in the magnitude of the trade winds is causing a warming of the Agulhas Current system on the east coast of South Africa. Han et al. (2010) noted an increase in anomalous south-easterly winds from the Southern Hemisphere. These changes in seasonal wind conditions could explain the wave height and direction trends. It is also reiterated that, prior to the March 2007 event, autumn (responsible for the largest events) was experiencing a negative trend in $H_{\max }$ and $H_{\mathrm{s}}$. Ultimately, the wave data set at our case study site is still too short to confidently establish any trends. However, Ruggiero et al. (2010), Theron et al. (2010) and Dodet et al. (2010) found similar increases in wave parameters that were determined to be statistically significant.

Only Durban's peak period and average wave direction showed statistically significant trends for the case study. The increase in wave direction is potentially important. At this location, the net littoral transport is from south to north and the average wave direction is from the south east. The increasing trend towards a more southerly wave direction implies that the littoral drift should be increasing. A simple application of the CERC formula (Shore protection manual, 1984) shows that an annual increase in wave direction of $0.91^{\circ}$ translates into a $1 \%$ annual increase in littoral drift. However, there is no increase evident in the measured sand bypass volumes. In conjunction with the fact that there has been a net sediment loss over the past $37 \mathrm{yr}$, this implies that there is sediment being removed from the system.

One possible sediment "sink" has been identified as the low-lying concrete stormwater outfalls that trap sediment movement. Other anthropogenic impacts are dams that trap sediments in rivers and sand-mining for construction. CSIR (2008) estimated that at least $400000 \mathrm{~m}^{3} /$ annum are mined from the eThekwini rivers. They further estimated that dams trap a third of the sediment that should reach the coastline. Although there are no significant dams on the rivers that flow into the harbour, all of the sediment deposited in the harbour is removed by maintenance dredging and dumped offshore. The cumulative effects of harbour dredging, dams, and sandmining result in a $63 \%$ reduction in the total fluvial yield into the area north of the harbour (CSIR, 2008).

The Richards Bay data on the other hand showed a statistically significant decrease in autumn wave direction, which may eventually have an important impact on Richards Bay's sand bypass scheme. In this case, the CERC formula translates the trend into a $0.3 \%$ annual decrease in littoral drift.

Large episodic flood events also contribute major sediment inputs to the sediment budget, because they erode accumulated sediments from rivers (CSIR, 2008). The Mgeni River is located immediately north of profile A (Fig. 3). Cooper et al. (2002) found that the Mgeni coastline had been steadily 


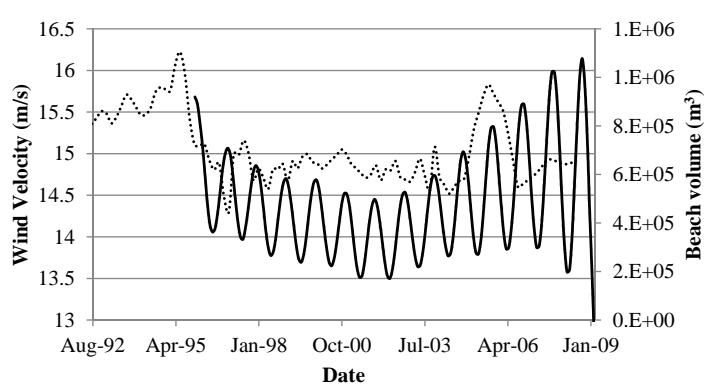

(a)

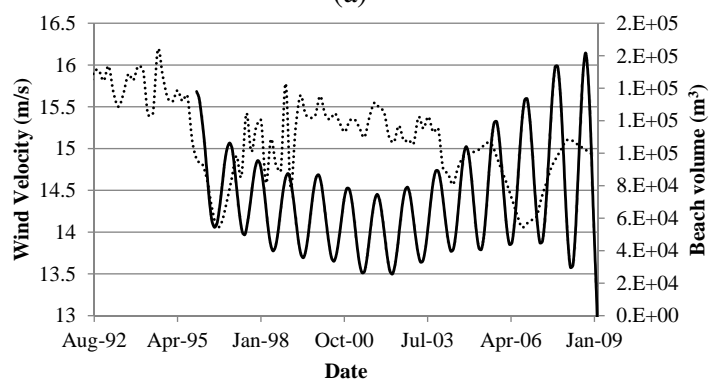

(c)

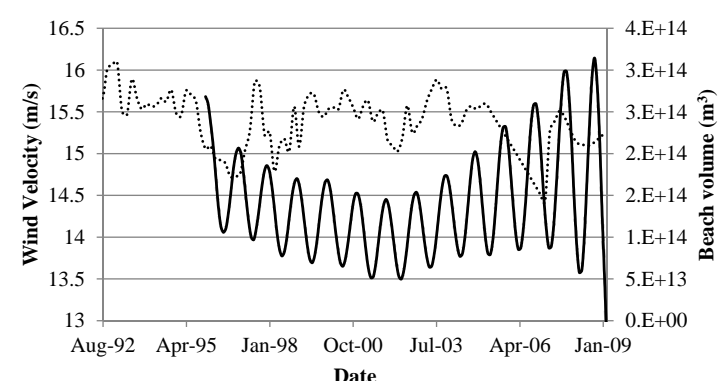

(b)

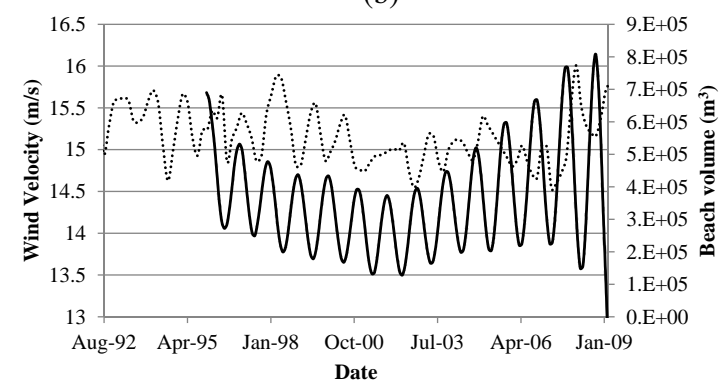

(d)

Fig. 10. The relationship between the wind trends (shown by the solid lines) and the beach volume trends (shown by the dotted lines) for the blocks (a) B-F, (b) 1-18, (c) 19-23, (d) BR6-BR9 (refer to Fig. 3).

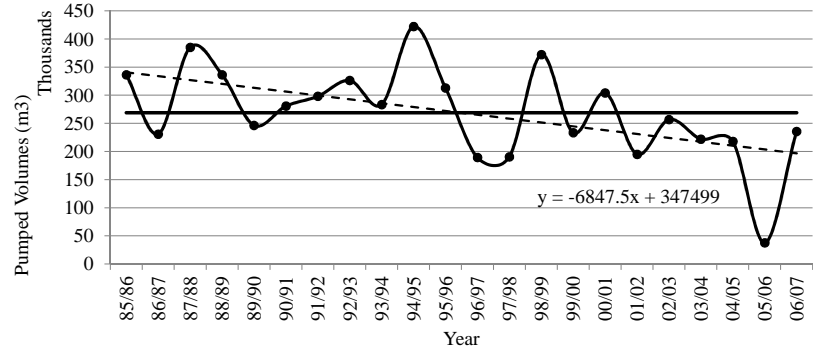

Fig. 11. Annual volumes pumped by the sand bypass scheme. The solid horizontal line shows the average annual volume while the dashed line shows a fitted linear trend.

eroding after 1931 but that following a large flood in 1987 the shoreline accreted and continued to do so for at least another three years, re-establishing the shoreline further seaward than that of 1931. The steady erosion between major flood events in 1917 and 1987 is consistent with the slow overall retreat of the coastline since the 1987 flood. Tinmouth et al. (2010), based on 2005/2006 measurements, reported that there was more sediment present within the Mgeni Estuary than prior to the 1987 flood. The KwaZulu-Natal coastline may require another major flood event to flush these sediments and balance the current sediment deficit.

Increases in storm frequency and intensity are potential contributors to beach erosion: the more storms or the longer their duration, the more erosion is likely to occur. Since sediment moves offshore during storm events and is then slowly worked back during calm conditions, the shorter the calm period between storms means consecutive storms could be experienced before the beaches have fully recovered. Durban's data show a decrease in storm duration and so is unlikely to be contributing to erosion. However, there was an increase in storm frequency and a corresponding decrease in average calm period. Storm events, as per the definition, were found to be increasing at 1.5 events per $100 \mathrm{yr}$. This slight increase in wave events may be related to the minor increase in cyclone days that has been reported by Mavume et al. (2009) in the south-west Indian Ocean. The increase in frequency is consistent with observations elsewhere by Komar and Allan (2008); Keim et al. (2004); Seymour (2002); Weisse and Stawarz (2004) and is possibly contributing to beach erosion. The limited $13 \mathrm{yr}$ of wind data were unable to provide statistically significant long-term trends but did provide an explanation for seasonal trends in beach morphology. The fact that wind has a seasonal effect on the beaches implies that any long-term trend in wind conditions will have a consequence on beach morphology. It was found that a number of storm events coincided with a $4.5 \mathrm{yr}$ extreme tidal cycle. The coincidence of these two erosion mechanisms compounds the erosions effects and is a demonstration of potential future sea level rise impacts (Chini et al., 2010). However, as with most of the wave parameters at this location, none of the changes in storm attributes are statistically significant and, apart from the results being consistent with other literature, their interpretation remains speculative. 
Sea level rise is a plausible contributor to chronic erosion. Bruun's rule with a sea level change of $0.0027 \mathrm{~m} \mathrm{yr}^{-1}$ (Mather, 2007) suggests that sea level rise can explain a significant portion of the observed erosion. The difference is expected to be made up by reduced fluvial sediment supply and the trends in wave and storm parameters.

\section{Conclusions}

Shoreline changes can have significant implications for coastal planning and management in developed coastal zones. It is therefore important to monitor and understand trends over decadal and longer time scales. In this study, $37 \mathrm{yr}$ of beach profile data on the east coast of South Africa have been analyzed for evidence of trends. This has been combined with an analysis of $18 \mathrm{yr}$ of local wave data to investigate corresponding trends in wave parameters and storm attributes and causative links to shoreline changes. To the authors' knowledge, this is the first such analysis done for the east coast of southern Africa.

The beach profile data show that the beaches in the region have been eroding over decadal time scales.

Most wave parameters showed an increasing trend except for the average significant wave height, which remained nearly constant over the $18 \mathrm{yr}$. However, only the trends in peak period and average direction are statistically significant at the $95 \%$ confidence level. There is evidence of an increase in storm frequency and decrease in the duration of calm periods, but neither are statistically significant. Local seasonal wind speed changes were found to be correlated to seasonal changes in beach morphology, but the data were unable to provide any insight on long-term trends. The net sediment loss experienced from beaches in the Durban area cannot therefore be attributed directly to wave climate and wind changes since they are too small to be major contributors. Nevertheless, should the observed trends continue, then they could play a more significant role in the future.

Sea level rise has been shown to be a plausible cause of the current morphological trends. Furthermore, the analysis has shown that the coincidence of large wave events with higher than average tide levels has coincided with extreme beach erosion events. This is a harbinger of the implications of future sea level rise due to global climate change.

We suggest that terrestrial anthropogenic activities such as the construction of dams and the mining of river sand have reduced the sediment supply and constitute an important factor in the observed erosion trends of the beaches in the case study area.

Trends in natural processes such as beach erosion are often assumed to be associated with global climate change. Although climate change and related factors can cause significant impacts, its role should not detract from other local anthropogenic factors that may have more significant impacts before the full effects of climate change are realized.
Acknowledgements. The authors wish to thank the eThekwini Municipality for the use of the beach profile data and the Transnet Port Authority for the use of wave and wind data.

Edited by: O. Katz

Reviewed by: J. Guillén, M. Bajo, and one anonymous referee

\section{References}

Bruun, P.: Sea Level Rise as a Cause of Shore Erosion, J. Waterway Port Coast Ocean Eng., 88, 117-130, 1962.

Callaghan, D. P., Nielsen, P., Short, A., and Ranasinghe, R.: Statistical simulation of wave climate and extreme beach erosion, Coast. Eng., 55, 375-390, 2008.

Chini, N., Stansby, P., Leake, J., Wolf, J., Roberts-Jones, J., and Lowe, J.: The impact of sea level rise and climate change on inshore wave climate: A case study for East Anglia (UK), Coast. Eng., 57, 973-984, 2010.

Cooper, J. A. G.: The role of extreme floods in estuary-coastal behaviour: contrasts between river- and tide-dominated microtidal estuaries, Sedimentary Geology, 150, 123-137, 2002.

Cooper, J. A. G. and Pilkey, O. H.: Sea-level rise and shoreline retreat: time to abandon the Bruun Rule, Global Planet. Change, 43, 157-171, 2004.

CSIR: Sand Supply from Rivers within the eThekwini Jurisdiction, implications for coastal sand budgets and resource economics, Report No. CSIR/NRE/ECO/ER/2008/0096/C, Stellenbosch, 2008.

Dai, S. B., Yang, S. L., and Cai, A. M.: Impacts of dams on the sediment flux of the Pearl River, southern China, Catena, 76, 3643, 2008.

Dang, T. H., Coynel, A., Orange, D., Blanc, G., Etcheber, H., and Le, L. A.: Long-term monitoring (1960-2008) of the riversediment transport in the Red River Watershed (Vietnam): Temporal variability and dam-reservoir impact, Sci. Total Environ., 408, 4654-4664, 2010.

Diedericks, H.: Personal Communication, eThekwini Municipality Coastal and Stormwater Department 166 KE Masinga Road, Durban, RSA, 29 June 2009, 2009.

Dodet, G., Bertin, X., and Taborda, R.: Wave climate variability in the North-East Atlantic Ocean over the last six decades, Ocean Model., 31, 120-131, 2010.

GESAMP: Anthropogenic Influences on Sediment Discharge to the Coastal Zone and Environmental Consequences, Joint Group of Experts on the Scientific Aspects of Marine Environmental Protection (GESAMP), GESAMP Reports and Studies No 52, UNESCO, 1994.

Golyandina, N., Nekrutkin, V., and Zhigljavsky, A.: Analysis of Time Series Structure: SSA and related techniques, Chapman and Hall/CRC, London, 305 pp., 2001.

Han, W., Meehl, G. A., Rajagopalan, B., Fasullo, J. T., Hu, A., Lin, J., Large, W. G., Wang, J., Quan, X., Trenary, L. L., Wallcraft, A., Shinoda, T., and Yeager, S.: Patterns of Indian Ocean sealevel change in a warming climate, Nat. Sci., 3, 546-550, 2010.

Hassani, H.: Singular Spectrum Analysis: Methodology and Comparison, J. Data Sci., 5, 239-257, 2007.

Hsu, S., Lin, F., Jeng, W., Chung, Y., Shawb, L., and Hung, K.: Observed sediment fluxes in the southwesternmost Okinawa Trough 
enhanced by episodic events: flood runoff from Taiwan rivers and large earthquakes, Deep-Sea Res. Pt. I, 51, 979-997, 2004.

Huang, G.: Time lag between reduction of sediment supply and coastal erosion, Int. J. Sediment Res., 26, 27-35, 2011.

Keim, B. D., Muller, R. A., and Stone, G. W.: Spatial and temporal variability of coastal storms in the North Atlantic Basin, Mar. Geol., 210, 7-15, 2004.

Kinmont, A.: Beach Erosion and Protection, The Institute of $\mathrm{Mu}-$ nicipal Engineers, Thirty third annual conference, Durban, 1954.

Knutson, T. R. and Tuleya, R. E.: Impact of $\mathrm{C}^{2}$ - Induced warming on simulated hurricane intensity and precipitation: Sensitivity to the choice of climate model and convective parameterization, J. Climate, 17, 3477-3495, 2004.

Komar, P. D. and Allan, C. J.: Increasing Hurricane-Generated Wave Heights along the U.S. East Coast and Their Climate Controls, J. Coast. Res., 24, 479-488, 2008.

Lambert, S.: Changes in winter cyclone frequencies and strengths in transient enhanced greenhouse warming simulations using two coupled climate models, Atmos.-Ocean, 42, 173-181, 2004.

Liquete, C., Canals, M., Ludwig, W., and Arnau, P.: Sediment discharge of the rivers of Catalonia, NE Spain, and the influence of human impacts, J. Hydrol., 366, 76-88, 2009.

Mather, A. A.: Linear and nonlinear sea-level changes at Durban, South Africa, South African J. Sci., 103, 509-512, 2007.

Mather, A. A.: Sea Level Rise for the East Coast of Southern Africa, Seventh International Conference of Coastal and Port Engineering in Developing Countries, COPEDEC VII, 2008, 173, 11, Dubai, UAE, 2008.

Mavume, A. F., Rydberg, L., Rouault, M., and Lutjeharms, J. R. E.: Climatology and Landfall of Tropical Cyclones in the SouthWest Indian Ocean, Western Indian Ocean J. Mar. Sci., 8, 15-36, 2009.

Perrie, W., Jiang, J., Long, Z., Toulany, B., and Zhang, W.: NW Atlantic wave estimates and climate change, Proceedings of the Eighth International Workshop on Wave Hindcasting and Forecasting, Oahu, Hawaii, 2004.

Pugh, D. T.: Tides, Surges and Mean Sea Level, John Wiley and Sons, Avon, United Kingdom, 472 pp., 1987.

Rouault, M., Penven, P., and Pohl, B.: Warming in the Agulhas Current system since the 1980's, Geophys. Res. Lett., 36, L12602, doi:10.1029/2009GL037987, 2009.

Rouault, M., Pohl, B., and Penven, P.: Coastal oceanic climate change and variability from 1982 to 2009 around South Africa, African J. Mar. Sci., 32, 237-246, 2010.

Rossouw, J.: Review of Existing Wave Data, Wave Climate and Design Waves for South African and South West African (Namibian) Coastal Waters, Coastal Engineering and Hydraulics National Research Institute for Oceanology Council for Scientific and Industrial Research, CSIR report, No. T/SEA 8401, Stellenbosh, 1984.

Rovira, A., Batalla, R. J., and Sala, M.: Fluvial sediment budget of a Mediterranean river: the lower Tordera (Catalan Coastal Ranges, NE Spain), Catena, 60, 19-42, 2005.
Ruggiero, P., Komar, P. D., and Allan, J. C.: Increasing wave heights and extreme value projections: The wave climate of the U.S. Pacific Northwest, Coast. Eng., 57, 539-552, 2010.

Seymour, R. J.: The Influence of Global Climate Change on Extreme Wave Occurrence on the West Coast of the United States, Proceedings of the 28th International Coastal Engineering Conference, Cardiff, 1, 52-60, 2002.

Shore protection manual: U.S. Army Engineer Waterways Experiment Station, US Government Printing Office, Washington, DC, 4th Edn., Vol. 2, 1984.

Singh, B.: Climate related global changes in the southern Caribbean: Trinidad and Tobago, Global Planet. Chang., 15, 93111, 1997.

Theron, A., Rossouw, M., Barwell, L., Maherry, A., Diedericks, G., and de Wet, P.: Quantification of risks to coastal areas and development: wave run-up and erosion, The 3rd biennial CSIR conference, Reference: NE20-PA-F, 2010.

Tinmouth, N: Mgeni Estuary, Pre- and Post- Inanda Dam Estuarine Dynamics. Unpublished MSc thesis, University of KwaZuluNatal, South Africa. 2010.

van Gent, M. R. A., van Thiel de Vries, J. S. M., Coeveld, E. M., de Vroeg, J. H., and van de Graaff, J.: Large-scale dune erosion tests to study the influence of wave periods, Coast. Eng., 55, 10411051, 2008.

van Thiel de Vries, J. S. M., van Gent, M. R. A., Walstra, D. J. R., and Reniers, A. J. H. M.: Analysis of dune erosion processes in large-scale flume experiments, Coast. Eng., 55, 1028-1040, 2008.

Wang, X. L. and Swail, V. R.: Changes of Extreme Wave Heights in Northern Hemisphere Oceans and Related Atmospheric Circulation Regimes, J. Climate, 14, 2204-2221, 2001.

Wang, X. L. and Swail, V. R.: Trends of Atlantic wave extremes as simulated in a 40-year wave hindcast using kinematically reanalyzed wind fields, J. Climate, 15, 1020-1035, 2002.

Wang, X. L., Zwiers, F. W., and Swail, V. R.: North Atlantic Ocean Wave Climate Change Scenarios for the 21 st Century, J. Climate, 17, 2368-2383, 2004a.

Wang, X. L., Swail, V. R., and Zwiers, F. W.: Changes in extratropical storm tracks and cyclone activity as derived from two global reanalyses and the Canadian CGCM2 projections of future, Proceedings of the Eighth International Workshop on Wave Hindcasting and Forecasting, Oahu, Hawaii, 2004b.

Weisse, R. and Stawarz, M.: Long-term changes and potential future developments of the North sea wave climate. Proceedings of the Eighth International Workshop on Wave Hindcasting and Forecasting, Oahu, Hawaii, 2004.

Woodroffe, C. D.: Coasts: form, process and evolution, Cambridge University Press, Cambridge, United Kingdom, 2003.

Zhang, K., Douglas, B. C., and Leatherman, S. P.: Global warming and coastal erosion, Climatic Change, 64, 41-58, 2004. 